\title{
Espaço sócio-ocupacional do assistente social: seu arcabouço jurídico-político
}

\section{The social worker's socio-occupational place: its juridical and political framework}

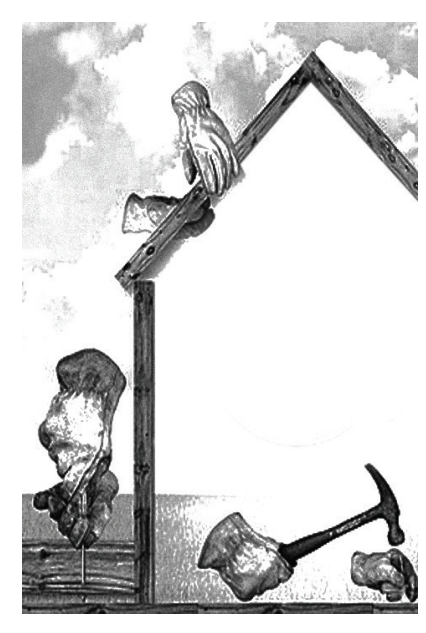

\section{Leila Baumgratz Delgado*}

Resumo: Frente aos desafios presentes no mundo do trabalho, que atingem também a formação e o exercício profissional do assistente social, o artigo tem por escopo reunir e comentar as salvaguardas jurídico-políticas disponíveis para o enfrentamento de tais questões. Pretende-se, ainda, avaliar se este aparato jurídico-político, construído historicamente pelos assistentes sociais, é suficiente para melhor qualificar seu fazer profissional e contrapor-se aos níveis de desemprego e precariedade do trabalho, possibilitando a ampliação do espaço ocupacional e condições de trabalho e remuneração adequadas.

Palavras-chave: Assistentes sociais. Estatuto legal-normativo. Espaço sócio-ocupacional.

\begin{abstract}
Since the current challenges in the world of contemporary work also come to the social worker's background and professional practice, the article aims at gathering and commenting the juridical and political provision available to handle such issues. We also intend to assess whether the juridical and political apparatus historically constructed by the social workers is enough to best qualify their professional practice and to face the unemployment rates and job instability, allowing an enlargement of the socio-occupational place, as well as adequate work conditions and pay.
\end{abstract}

Keywords: Social workers. Normative and legal act. Socio-occupational place.

* Assistente social, advogada, doutora em Serviço Social pela Universidade Federal do Rio de Janeiro (ESS/UFRJ), professora associado I da Universidade Federal de Juiz de Fora/MG, Brasil. E-mail: 1eilayacoub@ yahoo.com.br. 


\section{Introdução}

uito se tem escrito sobre o conjunto de reformas econômicas e
ideopolíticas que varreu o mundo capitalista a partir de meados da
década 1970. Suas causas, seu receituário, seus resultados e suas
consequências - sobretudo sobre o mundo do trabalho, das políticas públicas e dos direitos - foram e continuam sendo objeto de estudos e pesquisas por parte de intelectuais de diversas vertentes e áreas do conhecimento, de padrão nacional e internacional, dispensando, deste modo, uma explanação mais circunstanciada acerca deste vasto e intrincado tema. ${ }^{1}$

Para atender aos fins deste artigo, basta assinalar que ditas transformações no padrão de acumulação e regulação social modificaram substancialmente não só o paradigma do processo e gestão do trabalho capitalista ${ }^{2}$ e o sistema estatal, mas, também,

ao metamorfosear a produção e a reprodução da sociedade, atingem diretamente a divisão sociotécnica do trabalho, envolvendo modificações em todos os seus níveis [...] e incidem fortemente sobre as profissões, suas áreas de intervenção, seus suportes de conhecimento e de implementação, suas funcionalidades etc. (Netto, 1996, p. 87-9)

Por conseguinte, influenciam também as condições do exercício profissional do assistente social, alterando os requisitos e exigências da formação profissional, as demandas e o mercado de trabalho, os processos e as condições de trabalho profissionais (Iamamoto, apud CFESS/ABEPSS, 2009).

1. De acordo com Netto (1996), é no curso da década de 1970 - embora já evidenciadas na década anterior - que emergem as transformações societárias no âmbito estrutural e supraestrutural, que vão se consolidar nas décadas de 1980 e 1990, marcando significativamente uma nova configuração do mundo capitalista a partir da exaustão do modelo de regulação fordista-keynesiano. Para uma análise mais pormenorizada dessa processualidade, consultar também HARVEY, D. Condição pós-moderna: uma pesquisa sobre as origens da mudança cultural. São Paulo: Loyola, 1992; CHESNAIS, F. A mundialização do capital. São Paulo: Xamã, 1996; IAMAMOTO, M. V. Serviço Social em tempo de capital fetiche: capital financeiro, trabalho e questão social. 2. ed. São Paulo: Cortez, 2008; entre outros.

2. Entre tantas alterações podemos citar: redução do poder sindical, intensificação do trabalho, exigências de multifuncionalidade, metas de produtividade, salários variáveis, novas doenças ocupacionais e, sobretudo, a extinção e precarização de postos de trabalho através da adoção de modalidades de contratação flexíveis, incidindo mais acirradamente sobre a força de trabalho feminina, sobre os jovens e sobre os imigrantes. 
No que tange especificamente ao Brasil, a reforma neoliberal levada a cabo a partir do primeiro governo de FHC (1995-1998) teve repercussões profundas no ensino superior, manifestadas principalmente pela sua crescente privatização, mercantilização e simplificação (instalação de cursos sequenciais, ensino a distância e ciclos básicos) que, além de comprometer a indissociabilidade entre ensino, pesquisa e extensão, objetivam uma formação profissional aligeirada para atender apenas às exigências do mercado.

Os cursos de Serviço Social não escaparam à regra. Em 2001, tínhamos em funcionamento no país 85 cursos de Serviço Social. De acordo com informações oficiais colhidas no site e-mec, do Ministério da Educação, no governo Lula da Silva (2003-2010), os mesmos tiveram um crescimento de 297,3\%, alcançando, em abril de 2011, 377 cursos em funcionamento; 96\% dos quais - sem levar em conta sua qualidade - felizmente ainda eram presenciais, e entre eles apenas $14,8 \%$ eram gratuitos. ${ }^{3}$ Conforme a mesma fonte, passados apenas 10 meses, temos atualmente no Brasil 541 cursos de Serviço Social autorizados para funcionamento, dos quais $62 \%$ são presenciais e somente $9 \%$ são públicos.

Nas três últimas décadas a profissão passou por um processo de redimensionamento e renovação no âmbito de sua interpretação teórico-metodológica e ético-política, e melhor, qualificou-se, principalmente através da consolidação da pós-graduação stricto sensu e da produção científica acumulada a partir da década de 1980, adequando-se às exigências da contemporaneidade.

Na esfera sócio-ocupacional, a Constituição Cidadã de 1988, ao estabelecer o direito às políticas sociais, em especial à seguridade social, muito contribuiu para a expansão do mercado de trabalho dos assistentes sociais em função do incremento à rede socioassistencial, através da criação de importantes programas de atendimento a diversos segmentos da população. O espaço ocupacional ampliou-se também com atividades voltadas para implantação, orientação e representação em Conselhos de Políticas Sociais e de Direitos, organização e mobilização popular, elaboração de planos de assistência social, acompanhamento e avaliação de programas e projetos, ampliação e interiorização dos cursos de Serviço Social; além de assessoria e consultoria e requisições no campo da pesquisa.

3. Dados agrupados e cedidos por Débora Spotorno, mestranda do Programa de Pós-graduação em Serviço Social da Faculdade de Serviço Social (FSS) da Universidade Federal de Juiz de Fora. Disponível em: <emec.mec.gov.br>. Acesso em: 27 fev. 2012. 
Por outro lado, com os altos índices de desemprego e a desregulamentação e informalização das relações de trabalho - produtos da restauração do capital - e com a adoção do neoliberalismo trazendo consigo o retraimento das funções do Estado e redução dos gastos sociais, contribuindo para a crescente desresponsabilização deste no tocante às políticas públicas, e o retrocesso dos direitos sociais (Raichelis, apud CFESS/Abepss, 2009), agudizam-se as sequelas da questão social. A conjugação desses processos nas esferas produtiva e estatal leva ao crescimento e à diversificação do espaço ocupacional, assim como novas requisições e demandas para a profissão de Serviço Social (Iamamoto, apud CFESS/Abepss, 2009).

Entretanto, em que pese uma efetiva ampliação do mercado de trabalho para a categoria nas últimas décadas, estudos recentes têm revelado as intercorrências desastrosas das transformações societárias no âmbito do Serviço Social neste novo milênio, apontando para o crescimento do número de profissionais e das demandas, mas, ao mesmo tempo, para a perda ou precarização de postos de trabalho.

Frente às desconstruções e aos sabidos desafios presentes no mundo do trabalho contemporâneo - resultantes do capitalismo financeiro global e do desenvolvimento tecnológico e informacional -, como processos de precarização, desregulamentação e flexibilização das relações e condições de trabalho; altos níveis de desemprego; redução e mercantilização das políticas públicas; regressão dos direitos sociais e radicalização da questão social, atingindo o conjunto dos trabalhadores em geral e a formação e o exercício profissional do assistente social em particular, o presente artigo ${ }^{4}$ tem por escopo reunir e comentar as salvaguardas jurídico-políticas disponíveis para o enfrentamento de tais questões no âmbito do Serviço Social, emanadas principalmente de Resoluções do conjunto CFESS/CRESS.

Com sua publicação, pretende-se não só que ele tenha uma função pedagógica para a formação acadêmica e continuada dos assistentes sociais. Vislumbra-se também avaliar criticamente se este aparato jurídico-político - construído historicamente pelos assistentes sociais - tendo em vista seu estatuto de trabalhador as-

4. A elaboração deste artigo foi motivada principalmente pelo roteiro de estudos e reflexões apontados na disciplina de Laboratório em Áreas de Intervenção do curso de Serviço Social da Universidade Federal de Juiz de Fora (FSS/UFJF), que tratou da configuração do mercado de trabalho do assistente social no Brasil. Nosso agradecimento a todas as discentes da disciplina, especialmente a Andréa Machado, Fernanda Rodrigues e Mônica Carnevali pelas valiosas contribuições. Nosso agradecimento estende-se também a Nanci Simões, Agente Fiscal do Cress $6^{\mathrm{a}}$ R-JF, pela permanente interlocução e apoio técnico, e a profa. Rosangela Batistoni, coordenadora do Programa de Pós-graduação em Serviço Social da FSS/UFJF, pela leitura crítica e sugestiva. 
salariado, é hoje suficiente para melhor qualificar suas atribuições e competências exclusivas e contrapor-se aos níveis de desemprego e precariedade do trabalho profissional reinantes.

Fruto de uma vasta pesquisa documental acerca das legislações que criam e resguardam os diversos espaços ocupacionais do assistente social, em nosso estudo destacamos alguns artigos da Lei de Regulamentação da Profissão (Lei n. 8.662/1993) e do Código de Ética Profissional (Resolução CFESS n. 273/1993), além de Leis ordinárias, Resoluções e Projetos de Lei em tramitação no Congresso Nacional que dizem respeito, exclusivamente, ao tema em pauta, qual seja, a ampliação do espaço sócio-ocupacional e dos direitos dos assistentes sociais. ${ }^{5}$

\section{Os pilares normativos do exercício profissional}

Os dois grandes pilares normativos que regulamentam a profissão do assistente social no Brasil são a Lei n. 8.662 e o Código de Ética Profissional; a primeira, uma revisão da Lei n. 3.252/1957, datada de 7 de junho de 1993, é considerada como a principal legislação que regulamenta, disciplina e legitima a profissão do assistente social.

Primeiramente, no seu artigo $2^{\circ}$, estabelece que a profissão será exercida por aqueles que possuam o diploma de graduação em Serviço Social, oficialmente reconhecido e devidamente registrado no órgão competente. Os artigos $4^{\circ}$ e $5^{\circ}$ também merecem destaque referindo-se, respectivamente, às competências e às atribuições privativas do assistente social. As competências referem-se a qualificações profissionais de âmbito geral, reconhecidas tanto para os assistentes sociais como para outros profissionais de áreas afins. As atribuições privativas, por sua vez, são competências exclusivas do assistente social, decorrentes, especificamente, de sua qualificação profissional (Simões, 2007). A rigor, todas as 13 atribuições privativas definidas no artigo $5^{\circ}$ da citada Lei preservam o espaço ocupacional:

1) Coordenar, elaborar, executar, supervisionar e avaliar estudos, pesquisas, planos, programas e projetos na área de Serviço Social; 2) Planejar, organizar e administrar

5. Em função do limite de páginas, esta elaboração não abarcou as salvaguardas construídas no âmbito da formação profissional, a exemplo das Diretrizes Curriculares - as quais poderão vir a ser objeto de outro artigo. 
programas e projetos em unidades de Serviço Social; 3) Prestar assessoria e consultoria a órgãos da administração pública direta e indireta, empresas privadas e outras entidades, em matéria de Serviço Social; 4) Realizar vistorias, perícias técnicas, laudos periciais, informações e pareceres sobre a matéria de Serviço Social; 5) Assumir, no magistério de Serviço Social, tanto em nível de graduação como pós-graduação, disciplinas e funções que exijam conhecimentos próprios e adquiridos em cursos de formação regular; 6) Treinar, avaliar e supervisionar diretamente estagiários de Serviço Social; 7) Dirigir e coordenar unidades de ensino e cursos de Serviço Social, de graduação e pós-graduação; 8) Dirigir e coordenar associações, núcleos, centros de estudos e de pesquisa em Serviço Social; 9) Elaborar provas, presidir e compor bancas de exames e comissões julgadoras de concursos ou outras formas de seleção para assistentes sociais, ou onde sejam aferidos conhecimentos inerentes ao Serviço Social; 10) Coordenar seminários, encontros, congressos e eventos assemelhados, sobre assuntos de Serviço Social; 11) Fiscalizar o exercício profissional por meio dos conselhos federal e regionais; 12) Dirigir serviços técnicos de Serviço Social, em entidades públicas ou privadas; 13) Ocupar cargos e funções de direção e fiscalização da gestão financeira em órgãos e entidades representativas da categoria profissional.

O segundo (mas não menos importante) pilar que sustenta nossa profissão é o Código de Ética do Assistente Social, instituído pela Resolução CFESS n. 273/1993. Em suas páginas iniciais, contempla onze princípios fundamentais a serem incorporados não apenas no conteúdo da formação profissional, mas também no exercício da atividade profissional, "fundamentados na definição mais abrangente de compromisso com os usuários, com base na liberdade, democracia, cidadania, justiça e igualdade social" (Simões, 2007, p. 475), derivando daí o compromisso com a autonomia, a emancipação e a plena expansão dos indivíduos sociais, e a construção de uma nova ordem societária sem dominação e/ou exploração de classe, etnia e gênero.

O Título II afirma os direitos, responsabilidades e deveres do assistente social, e o Título III, capítulo II, regula as relações com as instituições empregadoras e outras. Para os fins deste artigo é importante citar a alínea "e" do artigo $2^{\circ}$ e a alínea "a" do artigo $7^{\circ}$ como direitos do assistente social, respectivamente: "desagravo público por ofensa que atinja a sua honra profissional" e "dispor de condições de trabalho condignas seja em entidade pública ou privada, de forma a garantir a qualidade do exercício profissional". Em relação ao primeiro, a Resolução CFESS n. 443/2003 regulamenta a alínea "e" do artigo $2^{\circ}$ e institui procedimentos para a realização do 
desagravo público, a cargo dos Conselhos Regionais, na defesa da atuação profissional e do reconhecimento e legitimação da profissão. ${ }^{6}$

No que tange à alínea “a” do artigo $7^{\circ}$, a Resolução CFESS n. 493/2006 dispõe sobre as condições éticas e técnicas do exercício profissional do assistente social, garantindo condições de trabalho e atendimento condignas, preservando o sigilo profissional e a qualidade dos serviços prestados aos usuários. Tendo em vista a exigência de que o trabalho profissional do assistente social deva ser executado de forma qualificada, a citada Resolução institui condições e parâmetros normativos claros e objetivos, estabelecendo como condição obrigatória para a realização de qualquer atendimento ao usuário do Serviço Social a existência de espaço físico suficiente e adequado para abordagens individuais e coletivas, com as seguintes características físicas: iluminação adequada ao trabalho diurno e noturno; ventilação adequada a atendimentos breves ou demorados (e com portas fechadas); recursos que garantam a privacidade do usuário naquilo que for revelado durante a intervenção profissional, e um local apropriado para a guarda do material técnico de caráter sigiloso.

\section{2. "Lei das 30 horas": a mais recente conquista}

Após longa espera e incansável mobilização, uma grande conquista foi obtida para toda a categoria profissional dos assistentes sociais com a aprovação da Lei n. 12.317, de 26 de agosto de 2010, que altera o artigo $5^{\circ}$ da Lei de Regulamentação da Profissão (Lei n. 8.662/1993), para instituir a duração do trabalho do assistente social em 30 horas semanais. No artigo $2^{\circ}$ enfatiza: "profissionais com contrato de trabalho em vigor na data de publicação desta Lei é garantida a adequação da jornada de trabalho, vedada a redução do salário".

6. Todo assistente social, devidamente inscrito no Cress, que no exercício da profissão for ofendido ou atingido em sua honra profissional ou que deixar de ser respeitado em seus direitos e prerrogativas previstas no artigo $2^{\circ}$ do Código de Ética Profissional, por pessoa física ou jurídica, poderá representar ao Cress de sua jurisdição o desagravo público. Feita a representação, o Conselho deverá criar uma comissão para averiguar a denúncia e, uma vez comprovada a ofensa profissional, o autor deverá se retratar pelos mesmos meios com que tornou pública a ofensa. A retratação pública do ofensor poderá ensejar o arquivamento da representação, desde que se mostre suficiente no sentido de restabelecer a imagem da profissão; caso contrário, o desagravo consistirá em um ato público do Conselho frente à sociedade e ao poder público. Se a ofensa resultar em demissão, o assistente social poderá requerer ao Ministério Público a sua reintegração (cf. Simões, 2007, p. 479). 
A motivação para a elaboração e aprovação da citada Lei está pautada no desgaste físico e mental a que é submetido o profissional de Serviço Social no trato com as múltiplas expressões da questão social, resultantes do modo de produção capitalista. ${ }^{7}$ Assim, pretendeu-se reduzir o tempo de trabalho que o assistente social fica exposto a situações de desgaste e estresse, possibilitando-lhe melhores condições de trabalho com a ampliação de seu tempo livre. Ademais, ao reduzir a jornada de trabalho para 30 horas semanais, reduz-se também o tempo de sobretrabalho a que os assistentes sociais (e os demais trabalhadores assalariados e contratados precariamente) estão submetidos numa sociedade produtora de mercadorias.

Entretanto, embora esse não tenha sido o espírito da Lei, é preciso atentar (e acompanhar) para duas possíveis consequências, não necessariamente excludentes, advindas da fixação da jornada de trabalho do assistente social em 30 horas semanais: por um lado, amplia-se a perspectiva de criação de mais postos de trabalho para a categoria tendo em vista a necessidade de suprir as requisições dos empregadores em tempo integral. Mas, por outro, a redução da jornada de trabalho em um momento de vigor de vínculos precários e baixos salários poderá resultar no avanço do duplo ou pluriemprego - variável que, associada a outras, mensura a precariedade do mercado de trabalho, e que em nossa categoria já atinge cerca de $20 \%$ dos assistentes sociais em atividade. ${ }^{8}$

De acordo com informações colhidas no "Observatório das 30 horas" podemos verificar que após ampla campanha de divulgação são inúmeros os organismos pú-

7. Em um dos muitos documentos elaborados em defesa das 30 horas, o CFESS afirma: "A redução da jornada de trabalho para os/as assistentes sociais se justifica ainda, pois são submetidos a longas e extenuantes jornadas e realizam atividades que provocam estado de profundo estresse, diante da convivência, minuto a minuto, com o limiar entre vida e morte, dor e tristeza, choro e lágrima. Ao lado do médico e do enfermeiro, o/a assistente social apresenta um dos maiores índices de estresse, fadiga mental, desgaste físico ou psicológico". Disponível em: <www.cfess.org.br>. Acesso em: 31 jan. 2012.

8. DELGADO, L. B. Relatório Final do Projeto de Pesquisa $O$ mercado de trabalho dos assistentes sociais em Minas Gerais e no Rio de Janeiro. Juiz de Fora, UFJF/FSS, 2009. Tendo como área de abrangência os estados de Minas Gerais e Rio de Janeiro, a referida pesquisa teve por objetivo traçar um perfil do mercado e condições de trabalho para os jovens assistentes sociais graduados a partir do primeiro governo Lula da Silva (2003/2006). Em face dos resultados alcançados foi possível estimar a proporção de jovens assistentes sociais desempregados, apontar as principais causas do desemprego e o modo como vem se operando a precarização do trabalho no interior da categoria, além de desnudar questões fundamentais que possam municiar a reflexão e as deliberações e iniciativas dos organismos de formação e de representação e organização dos assistentes sociais.

9. Instrumento eletrônico criado pelo CFESS para acompanhar a implantação da jornada de 30 horas semanais. Disponível em: <www.cfess.org.br>. Acesso em: 23 fev. 2012. 
blicos, privados, ONGs e entidades sem fins lucrativos em todas as partes do país que já se adequaram à Lei. Entretanto, como era de se esperar numa sociedade de classes, muitos empregadores ainda resistem a aplicá-la ou a aplicam de modo equívoco. ${ }^{10}$

\section{Aparato jurídico-político concernente ao espaço sócio-ocupacional}

Além da legislação de caráter genérico e abrangente, que acabamos de citar, e que legitima, qualifica e garante o exercício da profissão, a conduta ética e a duração máxima do trabalho para todos os assistentes sociais, há também aquelas que visam atingir segmentos profissionais exclusivos de acordo com a inserção ocupacional. Tendo em vista atingir os objetivos deste artigo, selecionamos a partir daqui textos legais específicos que visam tão somente ampliar e assegurar o espaço sócio-ocupacional do assistente social e a qualidade de atendimento aos usuários. Para fins didáticos, a citação e o comentário das legislações no âmbito do Serviço Social ou fora dele foram agrupados de acordo com as grandes áreas de intervenção, e por ordem cronológica.

\subsection{Na área sociojurídica}

Denominada Lei de Execução Penal (LEP), a Lei n. 7.210, de 11 de julho de 1984, tem por suposto a atuação de no mínimo um assistente social em cada estabelecimento penal. Vejamos: nos artigos $5^{\circ}$ e $6^{\circ}$ estabelece que os condenados, conforme os seus antecedentes e traços de personalidade, serão classificados para orientar a individualização da ação penal. Tal classificação será feita por uma Comissão Técnica que deverá também elaborar o programa individualizado da pena

10. Decisão emblemática e digna de nota é a Orientação Normativa n. 1 , de $1^{\circ}$ de fevereiro de 2011 , da Secretaria de Recursos Humanos do Ministério do Planejamento, Orçamento e Gestão (SRH-MPOG), que indica que nos órgãos da administração direta, autárquica e fundacional os assistentes sociais que optarem pela carga horária de 30 horas semanais deverão sofrer redução salarial proporcional em seus vencimentos - o que, já de partida, afronta o princípio constitucional da irredutibilidade dos salários. Mais impertinente e descabida é a Ação Direta de Inconstitucionalidade (ADIn n. 4.468) impetrada pela Confederação Nacional da Saúde - entidade que representa as empresas prestadoras de serviços de saúde - que contesta no STF a constitucionalidade da Lei n. 12.317/2010. Contra tais investidas, e competentemente, o conjunto CFESS/ Cress vem orientando e/ou representando a categoria política, administrativa e/ou judicialmente. 
privativa de liberdade do condenado ou preso provisório. $\mathrm{O}$ artigo $7^{\circ}$ estabelece que: "A Comissão Técnica de Qualificação, existente em cada estabelecimento, será presidida pelo diretor e composta, no mínimo, por 2 (dois) chefes de serviço, 1 (um) psiquiatra, 1 (um) psicólogo e 1 (um) assistente social". No artigo 23 define as atribuições do assistente social e, por último, a prescrição cabal que legitima a presença do assistente social nos estabelecimentos penais consta do artigo 75, inciso I: "O ocupante do cargo de diretor de estabelecimento deverá satisfazer os seguintes requisitos: ser portador de diploma de nível superior de Direito, ou Psicologia ou Ciências Sociais, ou Pedagogia ou Serviço Social”.

\subsection{Na área da saúde}

No âmbito da saúde, podemos inicialmente mencionar a Resolução n. 218/1997 do Conselho Nacional de Saúde (CNS). Considerando que a VIII Conferência Nacional de Saúde compreende a relação saúde/doença como um processo decorrente das condições de vida e trabalho, e a saúde como "direito de todos e dever do Estado", bem como acesso igualitário de todos aos serviços de promoção e recuperação da saúde, integralidade da atenção, e a importância da ação interdisciplinar na esfera da saúde, o CNS reconhece como profissionais de saúde de nível superior: assistentes sociais, biólogos, profissionais de educação física, enfermeiros, farmacêuticos, fisioterapeutas, fonoaudiólogos, médicos, médicos veterinários, nutricionistas, odontólogos, psicólogos e terapeutas ocupacionais.

Em 29 de março de 1999, fazendo uso da delegação de competência prevista na Resolução n. 218/1997 do CNS, ${ }^{11}$ a Resolução CFESS n. 383/1999, em seu artigo $1^{\circ}$, caracteriza o assistente social como profissional de saúde. Cuidadosa e criteriosamente, o artigo $2^{\circ}$ adverte para o fato de que o assistente social exerce suas atividades no largo espectro das políticas sociais, podendo atuar em outras áreas, não sendo, portanto, um profissional exclusivo da área de saúde.

As citadas resoluções, ao reconhecerem os assistentes sociais (bem como os demais) como profissionais de saúde, ampliam suas oportunidades de contratação e rendimentos, uma vez que assim poderão ter dois vínculos públicos de emprego,

11. O item II da citada Resolução delega aos Conselhos de classe das categorias de assistentes sociais, biólogos e médicos veterinários a caracterização como profissional de saúde. 
desde que pelo menos um deles seja junto à área de saúde. ${ }^{12}$ Entretanto, é necessário salientar que tal legislação, ao mesmo tempo que amplia as oportunidades de emprego, também pode contribuir para o aumento da precarização do trabalho destes profissionais (duplo ou pluriemprego, jornadas excessivas, vínculos precários, baixos salários, adoecimento etc.).

No campo da saúde mental, a Portaria n. 251 do Ministério da Saúde, de 31 de janeiro de 2002, que estabelece diretrizes e normas para a assistência hospitalar em psiquiatria na rede do SUS, e dá outras providências, estabelece que os hospitais psiquiátricos especializados ${ }^{13}$ deverão contar com pelo menos um assistente social para cada 60 pacientes, com 20 horas de assistência semanal, distribuídas no mínimo em 4 dias.

Ainda especificamente na área de saúde, na Resolução RDC/Anvisa n. 154, de 15 de junho de 2004, que estabelece o Regulamento Técnico para o funcionamento dos serviços de diálise, consta que "cada serviço de diálise deve ter a ele vinculado, no mínimo [...] 1 (um) assistente social para, junto aos demais profissionais da equipe multiprofissional, viabilizar a realização de ações voltadas aos pacientes renais crônicos"; tornando-se uma exigência legal a contratação de assistentes sociais nestes equipamentos de saúde.

\section{$3.3 \mathrm{Na}$ área da assistência}

Com a implantação do Sistema Único de Assistência Social (Suas), muito se ampliou o campo de atuação para nossa categoria, passando a assistência a ser atualmente um dos setores que mais requisita os assistentes sociais. Isso porque o Conselho Nacional de Assistência Social (CNAS), através da Resolução n. 269, de 13 de dezembro de 2006, aprovou a Norma Operacional Básica de Recursos Humanos do Suas (NOB-RH/Suas) que estabelece as equipes de referência para atuação no âmbito da proteção social básica e da proteção especial de média e alta complexidade.

12. Conforme estabelecido na Constituição Federal de 1988, artigo 37, inciso XVI: "é vedada a acumulação remunerada de cargos públicos, exceto quando houver compatibilidade de horários: a) a de dois cargos de professor; b) a de um cargo de professor com outro técnico ou científico; c) a de dois cargos ou empregos privativos de profissionais de saúde, com profissões regulamentadas".

13. Conforme a citada Portaria, considera-se como hospital psiquiátrico aquele cuja maioria de leitos se destine ao tratamento especializado de clientela psiquiátrica em regime de internação. 
De acordo com a NOB/RH-Suas (p. 19), entende-se por equipes de referência aquelas constituídas por servidores efetivos ${ }^{14}$ responsáveis pela organização e oferta de serviços, programas, projetos e benefícios de proteção social básica e especial, levando-se em consideração o número de famílias e indivíduos referenciados, o tipo de atendimento e as aquisições que devem ser garantidas aos usuários. Assim, em municípios com até 2.500 famílias referenciadas (Pequeno Porte I) o Centro de Referência de Assistência Social (Cras) deverá contar com dois técnicos de nível superior, sendo um assistente social. Em municípios com até 3.500 famílias referenciadas (Pequeno Porte II), deverá haver três técnicos de nível superior, sendo dois assistentes sociais. E em municípios de médio e grande porte, metrópoles e Distrito Federal, a cada 5.000 famílias referenciadas, em cada Cras deverá haver quatro técnicos de nível superior, sendo dois assistentes sociais.

No que se refere à proteção social de média complexidade, no âmbito dos Centros de Referência Especializado de Assistência Social (CREAS), a NOB-RH/ SUAS estabelece que em municípios em gestão inicial e básica, com capacidade de atendimento de 50 pessoas/indivíduos, deverá haver um assistente social; e em municípios em gestão plena e estados com serviços regionais, com capacidade de atendimento de 80 pessoas/indivíduos, deverá haver dois assistentes sociais. Com relação à assistência de alta complexidade, a NOB assim define: a) atendimento em pequenos grupos (abrigo institucional, casa-lar e casa de passagem): um assistente social para atendimento a, no máximo, 20 usuários acolhidos; b) Família Acolhedora: um assistente social para acompanhamento de até 15 famílias acolhedoras e atendimento a até 15 famílias de origem dos usuários atendidos nesta modalidade; c) República: um assistente social para atendimento a, no máximo, 20 usuários em até dois equipamentos e d) Instituições de Longa Permanência para Idosos (ILPIs): um assistente social para atendimento direto.

\subsection{A tabela Referencial de Honorários do Serviço Social}

Em face das transformações operadas na organização e na estrutura da produção e do Estado capitalista, repercutindo nas relações de trabalho em geral e nas

14. Embora a legislação se refira a servidores efetivos, o que se verifica é que muitas contratações feitas por estados e municípios são precárias: seja através de terceirização, contratos temporários, ONGs, prestação de serviços etc. 
formas de contratação em particular, verificou-se no âmbito da profissão de Serviço Social (assim como em outras) um percentual significativo de assistentes sociais exercendo suas competências e atribuições privativas sem a cobertura de qualquer vínculo empregatício, por meio da prestação de serviços, o que comumente se designa como trabalho autônomo. Pesquisa nacional organizada pelo CFESS com dados coletados em 2004 já revelava que cerca de $6 \%$ dos assistentes sociais no Brasil são autônomos; no nordeste representam $12,2 \%$ da categoria. ${ }^{15} \mathrm{Na}$ região sudeste, tomados apenas os estados de Minas Gerais e Rio de Janeiro, 9,5\% dos profissionais prestam serviços como autônomos. ${ }^{16} \mathrm{Na}$ verdade, o que se observa é que boa parte do trabalho assalariado vem sendo substituído pelo trabalho autônomo ou prestação de serviços como forma de escamotear a relação de emprego. Conforme Raichelis (2009, p. 383),

intensificam-se os processos de subcontratação de serviços individuais dos assistentes sociais por parte de empresas de serviços ou de assessoria na prestação de serviços aos governos, acenando para o exercício profissional privado (autônomo), temporário, por projeto, por tarefa, em função das novas formas de gestão das políticas sociais.

Para salvaguardar mínimas condições de remuneração para este percentual crescente de assistentes sociais precarizados, em 5 de setembro de 2001 o CFESS, através da Resolução n. 418/2001, instituiu a Tabela Referencial de Honorários do Serviço Social (TRHSS). Em última análise, criou o valor mínimo da hora técnica para aqueles desprovidos de qualquer vínculo empregatício, estatutário ou de natureza assemelhada.

$\mathrm{O}$ artigo $7^{\circ}$ da citada Resolução prescreve também que os gastos decorrentes da prestação de serviços, tais como alimentação, transporte, hospedagem, certidões e cópias, correrão por conta do contratante.

Posteriormente, objetivando valorizar a qualificação acadêmica do assistente social, a Resolução CFESS n. 467/2005 deu nova redação à Resolução n. 418/2001, estabelecendo gradações no valor da hora técnica de acordo com o nível de formação

15. CFESS (Org.). Assistentes sociais no Brasil: elementos para o estudo do perfil profissional. Brasília: Virtual/CFESS, 2005.

16. DELGADO, L. B. O mercado de trabalho dos assistentes sociais em Minas Gerais e no Rio de Janeiro (Relatório Final). Juiz de Fora: UFJF/FSS, 2009. 
pós-graduada do assistente social. Os valores da hora técnica que serão referência até agosto de 2012 são os seguintes: graduados: R \$ 87,26; especialistas: R \$ 97,99; mestres: 123,51 ; doutores: $\mathrm{R} \$ 139,62 .{ }^{17}$

\section{A ação fiscalizadora dos conselhos}

Conforme expusemos até aqui, podemos constatar que ao longo de seu percurso e consolidação como profissão, especialmente a partir da última década do século passado, foram criados vários instrumentos legais que garantem e ampliam o espaço sócio-ocupacional e as condições de trabalho e remuneração dos assistentes sociais, seja na esfera da organização política da categoria, seja na esfera da própria sociedade, como reconhecimento do valor de uso da profissão.

No período compreendido entre os anos de 1981 e 1984, o então denominado conjunto CFAS/Cras (Conselho Federal de Assistentes Sociais e Conselhos Regionais de Assistentes Sociais) criou as Comissões de Orientação e Fiscalização (Cofis), contratando assistentes sociais para o exercício da fiscalização do exercício profissional. Dando continuidade a essa necessária e relevante tarefa, a Resolução CFESS n. 512/2007 reformulou as normas gerais para o exercício da fiscalização profissional e atualizou a Política Nacional de Fiscalização, ficando a cargo dos Cress realizá-la.

A Política Nacional de Fiscalização constituiu-se como o produto advindo da necessidade de dinamizar a organização de estratégias políticas e jurídicas unificadas na perspectiva de defesa, valorização, publicização e fortalecimento da profissão em face dos dilemas da atualidade, assegurando a defesa do espaço ocupacional e a qualidade de atendimento aos usuários do Serviço Social. ${ }^{18}$

Além da Política Nacional de Fiscalização, a ação fiscalizadora dos conselhos regionais de Serviço Social é norteada pelos seguintes instrumentos: Lei n. 8.662/1993,

17. É necessário salientar que não encontramos investigações que confirmem a obediência à TRHSS.

18. O artigo $5^{\circ}$, parágrafo $1^{\circ}$, da Resolução n. 512/2007, estabelece que “a ação fiscalizadora dos Cress deve ser definida em conformidade com a Política Nacional de Fiscalização do conjunto CFESS/Cress articulando-se as dimensões: afirmativa de princípios e compromissos conquistados; político-pedagógica; normativa e disciplinadora". 
Código de Ética do Assistente Social (1993), Diretrizes Curriculares da Abepss (1996) e resoluções e pareceres jurídicos do conjunto CFESS/Cress.

Às Cofis, entre as várias atividades que lhe são atribuídas, cabe a fiscalização rotineira do exercício profissional dos assistentes sociais e de pessoas jurídicas que prestam serviços específicos de serviço social a terceiros, além da fiscalização eventual para apurar denúncias e recomendar ao Conselho Pleno dos Cress as providências cabíveis. Quando a aplicação de medidas ou sanções extrapolar a competência dos Cress, estes deverão exigi-las formalmente do organismo competente.

\section{Projetos de lei em tramitação}

Os projetos de lei representam o esforço e a mobilização do conjunto CFESS/ Cress, contando com a costumeira parceria da Abepss (Associação Brasileira de Ensino e Pesquisa em Serviço Social) e da Enesso (Executiva Nacional de Estudantes de Serviço Social) na busca de maior legitimidade para a profissão de Serviço Social. Atualmente alguns projetos de lei estão em discussão na Câmara Federal, podendo não só garantir melhores condições de trabalho e remuneração para a categoria, mas também reforçar a legitimidade e ampliar o espaço socioprofissional do Serviço Social. São eles:

\subsection{Projeto de Lei n. 5.278/2009, dispõe sobre piso salarial profissional}

De autoria da deputada Alice Portugal (PCdoB-BA), propõe alteração na Lei n. 8.662/1993 definindo piso salarial para a categoria no valor de $\mathrm{R} \$ 3.720,00$ (três mil e setecentos e vinte reais) para uma jornada de 30 horas semanais e seis horas diárias, e reajuste anual com base na variação acumulada do Índice Nacional de Preços ao Consumidor (INPC). O Projeto de Lei (PL) foi aprovado com ressalvas na Comissão de Trabalho, de Administração e Serviço Público (CTASP) da Câmara Federal e atualmente aguarda Parecer na Comissão de Finanças e Tributação (CFT). 


\subsection{Projeto de Lei n. 3.688/2000, PLC/2007, e Projetos de Lei ns. 6.478/2009 e 6.874/2010, que dispõem sobre a prestação de serviços de Psicologia e Serviço Social nas escolas públicas de educação básica}

A primeira iniciativa data de 2000 (PL n. 3.688), apresentado na Câmara Federal pelo deputado José Carlos Elias (PTB-ES), e aprovado em 2007. Transformado em Projeto de Lei Complementar no Senado (PLC/2007), foi aprovado em novembro de 2010 e, de acordo com o regimento interno, uma vez que recebeu emendas no Senado, retorna à Câmara para nova aprovação. No momento aguarda Parecer na Comissão de Seguridade Social e Família (CSSF).

Nessa mesma direção, em 2009 o deputado Fábio Faria (PMN-RN) apresentou na Câmara dos Deputados o PL n. 6.478/2009, que propõe a criação do cargo de assistente social nos quadros funcionais das escolas públicas de ensino fundamental e médio de todo o país. No ano seguinte, a deputada Sueli Vidigal (PDT-ES) apensou o PL n. 6.874/2010, que propõe a alteração da Lei de Diretrizes e Bases da Educação (LDB) para a criação de núcleo psicossocial composto por assistente social e psicólogo nas escolas públicas de ensino fundamental, para atendimento a educandos vítimas de violência doméstica, maus-tratos e dependência química.

Estes dois últimos projetos de lei passaram a tramitar juntos, por se tratar de matéria similar, e aguardam atualmente Parecer nas Comissões de Seguridade Social e Família (CSSF), Educação e Cultura (CEC) e Constituição e Justiça (CCJC) da Câmara Federal.

Assim, considera-se de muita relevância a inserção de assistentes sociais no quadro profissional da educação, já que nesse espaço institucional são apresentadas complexas questões sociais que o conhecimento pedagógico não consegue enfrentar sozinho, necessitando de outros saberes e intervenções como os do assistente social.

\subsection{Projeto de Lei n. 3.145/2008, dispõe sobre contratação de assistentes sociais}

Também de autoria da deputada Alice Portugal, apresentado em abril de 2008 na Câmara Federal, dispõe sobre a obrigatoriedade de contratação de assistentes sociais por todas as instituições públicas e empresas urbanas e rurais que atuam na 
produção e na prestação de serviços de assistência social, planejamento, previdência, habitação, educação, saúde e ação comunitária.

De acordo com o texto do projeto, observada a natureza do estabelecimento empregador relacionada anteriormente, deverá ser contratado um assistente social para cada grupo de: a) mil empregados; b) quatrocentos alunos, c) cem crianças, adolescentes ou idosos; d) oitenta detentos; e) trinta leitos; f) sessenta usuários de serviços de reabilitação física; g) duzentos usuários de ambulatórios; e h) mil habitantes.

Aprovado com restrições na CSSF, o PL foi encaminhado para apreciação à Comissão de Constituição e Justiça e Cidadania (CCJC), para análise de sua constitucionalidade, e para a Comissão de Trabalho, de Administração e Serviço Público (CTASP), sendo também recomendada sua distribuição para a Comissão de Finanças e Tributação (CFT) para averiguação de sua compatibilidade financeira e orçamentária, uma vez que o referido projeto também prevê a contratação de assistentes sociais por instituições governamentais, resultando em aumento de despesas com pessoal.

5.4 Projeto de Lei n. 6.271/2009, dispõe sobre a inclusão de assistentes sociais nas equipes da Estratégia de Saúde da Família

Finalmente, o Projeto de Lei n. 6.271/2009 apresentado pelo deputado federal Maurício Trindade (PR-BA), que dispõe sobre a inclusão obrigatória de assistentes sociais na composição das equipes da Estratégia de Saúde da Família. Encaminhado para parecer junto à CFT, CCJC e CSSF da Câmara Federal, no momento aguarda aprovação, com emendas, na CSSF.

\section{Conclusão}

Desde os anos 1990, o Serviço Social brasileiro vem se consolidando como uma profissão que efetivou um salto significativo em sua qualificação e elaboração teórica, além do fortalecimento de suas formas de representação nas esferas acadêmica e profissional, e da ampliação de sua presença política na sociedade (Iamamoto, 2008). 
Conforme informações colhidas no CFESS, dos 60 mil profissionais existentes no ano 2000, somos hoje cerca de 110 mil assistentes sociais exercendo suas competências e atribuições em torno de um projeto profissional hegemônico, inovador e crítico, com fundamentos históricos e teórico-metodológicos pautados na tradição marxista, apoiado em valores e princípios éticos. Este projeto profissional adquire materialidade no conjunto das regulamentações profissionais que foram citadas ao longo deste artigo: a Lei de Regulamentação da Profissão (1993), o Código de Ética do Assistente Social (1993), as Diretrizes Curriculares norteadoras da formação profissional (1996), além das resoluções e pareceres jurídicos do CFESS.

A legitimidade, expressividade e expansão da profissão no curso das três últimas décadas também se manifestam no poder de organização e mobilização da categoria, na conquista de direitos e na ampliação dos espaços ocupacionais. Somos requisitados nas esferas pública e privada; na indústria, nos serviços, nas ONGs e entidades sem fins lucrativos.

Conforme expusemos anteriormente, através de textos legais tornou-se obrigatória a contratação de assistentes sociais nas principais áreas de intervenção, como saúde, assistência e sociojurídica. Ademais, como vimos, tramitam hoje na Câmara Federal Projetos de Lei que dispõem sobre a exigência de contratação de assistentes sociais em empresas, ambulatórios, hospitais, ONGs e comunidades.

A busca por melhores condições de trabalho e de atendimento adequado aos usuários está, por exemplo, amparada pelas Resoluções ns. 443/2003 e 493/2006 do CFESS - que tratam respectivamente dos procedimentos para a realização de desagravo público e sobre condições éticas e técnicas do exercício profissional -, e mais recentemente pela Lei n. 12.317/2010, que fixa a jornada de trabalho em 30 horas semanais.

Todavia, embora as salvaguardas jurídico-políticas, construídas e em construção, reunidas nesta investigação contribuam decisivamente para o reconhecimento e visibilidade institucional do Serviço Social e configurem-se como de extrema necessidade para a qualificação e ampliação do espaço profissional, temos clareza da sua limitada efetividade em face dos altos índices de desemprego e precariedade do trabalho impostos pela reestruturação produtiva e pelo neoliberalismo. Alia-se a isso o fato de que nas últimas décadas, com a expansão/privatização desenfreada do ensino superior e seu deliberado aligeiramento e simplificação, amplia-se ainda mais o exército de reserva de assistentes sociais e reduz-se o valor de nossa força de 
trabalho. Em pesquisa realizada com 167 jovens assistentes sociais graduados entre os anos 2003/2006 nos estados de Minas Gerais e Rio de Janeiro, verificamos que $18,6 \%$ deles estavam desempregados, e entre os empregados, $47 \%$ tinham contratos precários (autônomos, temporários, contratos de gestão, part time e outros). ${ }^{19}$

Assim, objetivando acrescer elementos à discussão acerca dos rumos para a ampliação e melhoria do espaço ocupacional do assistente social concluímos que, para além da luta permanente e coletiva junto aos demais trabalhadores e no âmbito de nossas organizações sindicais nos locais de trabalho, indicamos a dinamização do trabalho de fiscalização realizado pelas Cofis, a mobilização para a aprovação dos Projetos de Lei em trâmite e a criação de um observatório nacional sobre condições de trabalho e trabalho dos assistentes sociais. Todavia, cremos que tais iniciativas serão inócuas se individual e coletivamente não adotarmos uma posição crítica e ofensiva frente ao modelo de formação universitária em curso que, ao tratar a educação como mercadoria, transforma-se em uma fábrica de diplomas debilitando a formação acadêmica e profissional. Isso significa afirmar que no curto prazo torna-se imperativo e urgente ampliar o arcabouço legal normativo concernente à formação profissional - a exemplo do exame de proficiência -, sem o qual não será possível enfrentar os altos índices de desemprego e precariedade do trabalho impostos pela "condição pós-moderna" (Harvey, 1992).

\section{Recebido em 3/7/2012 - Aprovado em 10/12/2012}

\section{Referências bibliográficas}

BRASIL. Constituição da República Federativa do Brasil de 1988. Disponível em: <www. planalto.gov.br>. Acesso em: 28 maio 2012.

. Lei n 7.210, de 11 de julho de 1984 (LEP). Institui a Lei de Execução Penal. Disponível em: <www.planalto.gov.br>. Acesso em: 2 ago. 2011.

BRASIL. Lei n. 12.317, de 26 de agosto de 2010. Acrescenta dispositivo à Lei n. 8.662, de 7 de junho de 1993, para dispor sobre a duração do trabalho do assistente social. Disponível em: <www.planalto.gov.br>. Acesso em: 28 maio 2012.

19. DELGADO, L. B. Op. cit. 
BRASIL. Portaria GM/MS n. 251, de 31 de janeiro de 2002. Estabelece diretrizes e normas para a assistência hospitalar em psiquiatria, reclassifica os hospitais psiquiátricos, define e estrutura a porta de entrada para as internações psiquiátricas na rede do SUS e dá outras providências. Disponível em: <www.conselho.saude.gov.br>. Acesso em: 28 maio 2012.

. Projeto de Lei n. 3.145/2008. Disponível em: <www.camara.gov.br>. Acesso em: 21 jun. 2012.

. Projeto de Lei n. 5.278/2009. Disponível em: <www.camara.gov.br>. Acesso em: 21 jun. 2012.

. Projeto de Lei n. 6.271/2009. Disponível em: <www.camara.gov.br>. Acesso em: 22 jun. 2012.

. Projeto de Lei n. 6.478/2009. Disponível em: <www.camara.gov.br>. Acesso em: 22 jun. 2012.

. Projeto de Lei n. 6.874/2010. Disponível em: <www.camara.gov.br>. Acesso em: 22 jun. 2012.

. Resolução CFESS n. 273/1993. Institui o código de ética profissional e dá outras providências. Disponível em: <www.cfess.org.br>. Acesso em: 29 maio 2012.

. Resolução CFESS n. 383/1999. Caracteriza o assistente social como profissional da saúde. Disponível em: <www.cfess.org.br>. Acesso em: 29 maio 2012.

. Resolução CFESS n. 418/2001. Tabela Referencial de Honorários do Serviço Social. Disponível em: <www.cfess.org.br>. Acesso em: 29 maio 2012.

. Resolução CFESS n. 443/2003. Institui procedimentos para a realização de desagravo público, e regulamenta a alínea "e" do artigo $2^{\circ}$ do Código de Ética do Assistente Social/Altera e revoga a Resolução CFESS n. 294/94. Disponível em: <www.cfess.org.br>. Acesso em: 30 maio 2012.

. Resolução CFESS n. 467/2005. Disponível em: <www.cfess.org.br>. Acesso em: 30 maio 2012.

. Resolução CFESS n. 493/2006. Dispõe sobre as condições éticas e técnicas do exercício profissional do assistente social. Disponível em: <www.cfess.org.br>. Acesso em: 30 maio 2012.

. Resolução CFESS n. 512/2007. Reformulação das normas gerais para o exercício da Fiscalização Profissional e atualização da Política Nacional de Fiscalização. Disponível em: <www.cfess.org.br>. Acesso em: 30 maio 2012.

. Resolução CNS n. 218/1997. Reconhece o assistente social e outros como profissionais de saúde. Disponível em: <www.conselho.saude.gov.br>. Acesso em: 28 maio 2012. 
BRASIL. Resolução n. 269, de 13 de dezembro de 2006. Aprova a Norma Operacional Básica de Recursos Humanos do Sistema Único de Assistência Social (NOB-RH/Suas). Disponível em: <www.mds.gov.br>. Acesso em: 28 maio 2012.

. Resolução RDC/Anvisa n. 154/2004. Estabelece o Regulamento Técnico para o funcionamento dos Serviços de Diálise. Disponível em: <www.anvisa.gov.br>. Acesso em: 29 maio 2012.

CFESS (Org.). Assistentes sociais no Brasil: elementos para o estudo do perfil profissional. Brasília: Virtual/CFESS, 2005.

(Org.). Código de Ética do Assistente Social. Lei n. 8.662/93 de Regulamentação da Profissão, Brasília: CFESS, 2006.

CHESNAIS, F. A mundialização do capital. São Paulo: Xamã, 1996.

DELGADO, L. B. O mercado de trabalho dos assistentes sociais em Minas Gerais e no Rio de Janeiro (Relatório). Juiz de Fora: UFJF/FSS, 2009.

HARVEY, D. Condição pós-moderna: uma pesquisa sobre as origens da mudança cultural. São Paulo: Loyola, 1992.

IAMAMOTO, M. V. Serviço Social em tempo de capital fetiche: capital financeiro, trabalho e questão social. 2. ed. São Paulo: Cortez, 2008.

. Os espaços sócio-ocupacionais do assistente social. In: Serviço Social: direitos e competências profissionais. Brasília: CFESS/Abepss, 2009. p. 341-375.

NETTO, J. P. Transformações societárias e Serviço Social: notas para uma análise prospectiva da profissão no Brasil. Serviço Social \& Sociedade. São Paulo, n. 50, p. 87-132, 1996.

RAICHELIS, R. O trabalho do assistente social na esfera estatal. In: Serviço Social: direitos e competências profissionais. Brasília: CFESS/Abepss, 2009. p. 377-391.

SIMÕES, C. Curso de direito do Serviço Social. São Paulo: Cortez, 2007. 